\title{
Understanding Rate Accelerations for Diels-Alder Reactions in Solution using Enhanced QM/MM Methodology
}

\section{Orlando Acevedo and William L. Jorgensen}

Contribution from the Department of Chemistry and Biochemistry, Auburn University, Auburn, Alabama 36849 and the Department of Chemistry, Yale University, 225 Prospect Street, New Haven, Connecticut 06520-8107.

Supporting Material

Figure S1. Diels-Alder Reaction between Cyclopentadiene and Naphthoquinone in Water........1

Table S1. Computed Gas-phase Activation Barrier between Cyclopentadiene and MVK..........2

Figure S2. Comparison of PM3 and PDDG/PM3 Transition Structures ........................2

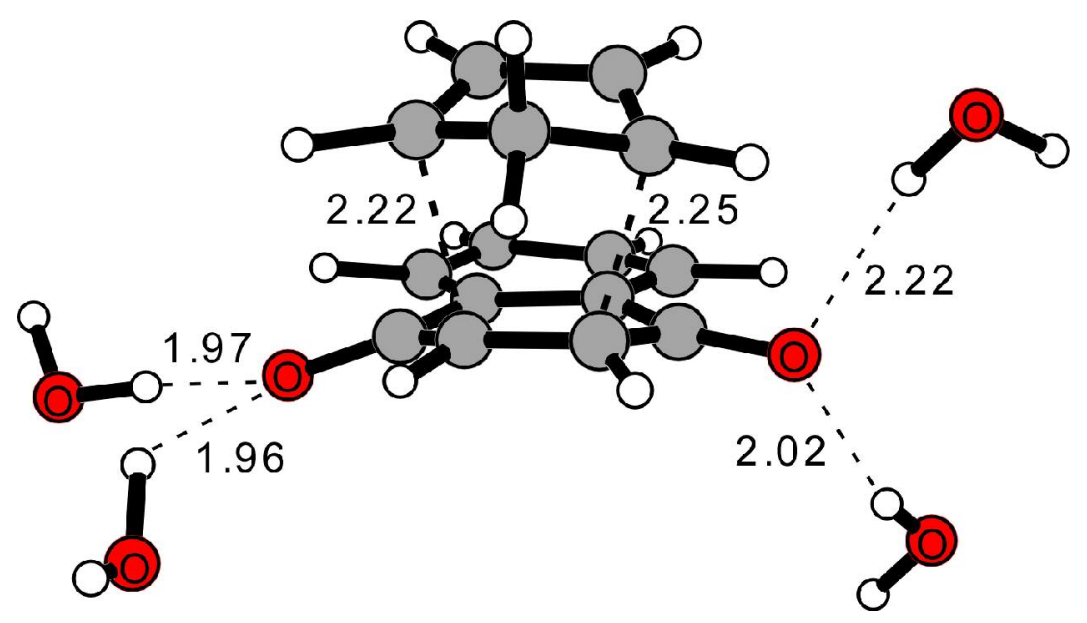

Figure S1. Typical snapshot of the Diels-Alder reaction between cyclopentadiene and 1,4naphthoquinone in water from the $\mathrm{QM} / \mathrm{MM} / \mathrm{MC}$ simulations (only water molecules nearest the solute are illustrated). Distances in Á. 
Table S1. Calculated gas-phase activation barriers $(\mathrm{kcal} / \mathrm{mol})$ for the Diels-Alder reaction between cyclopentadiene and methyl vinyl ketone.

\begin{tabular}{ccccc}
\hline & $\mathrm{AM}^{\mathrm{a}}$ & $\mathrm{PM}^{\mathrm{a}}$ & $\mathrm{PDDG}^{\mathrm{a}} \mathrm{PM}$ & $\mathrm{MP}^{2} / 6-31 \mathrm{G}^{* \mathrm{~b}}$ \\
\hline endo-cis & 30.1 & 33.8 & 33.7 & 15.9 \\
endo-trans & 30.1 & 33.9 & 33.2 & 18.4 \\
exo-cis & 28.3 & 32.8 & 32.7 & 16.2 \\
exo-trans & 30.3 & 33.0 & 33.7 & 20.7 \\
\hline
\end{tabular}

${ }^{\mathrm{a}}$ Values from ref. 17. ${ }^{\mathrm{b}}$ Ref. 37. Using 6-31G* geometries.

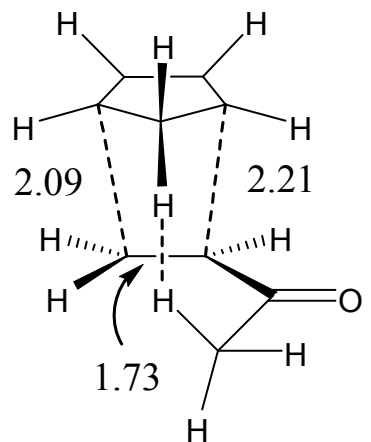

PM3

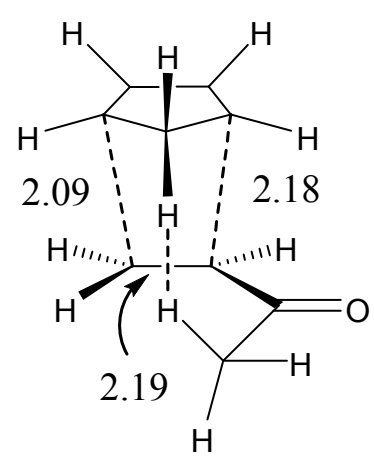

PDDG/PM3

Figure S2. PM3 and PDDG/PM3 geometries for the exo s-trans transition structure for the reaction between cyclopentadiene and methyl vinyl ketone. 